\title{
Risk-corrected impact of mechanical versus bioprosthetic valves on long-term mortality after aortic valve replacement
}

\author{
Ole Lund, MD, PhD, and Martin Bland, MSc, PhD
}

Earn CME credits at http://cme.

3 Supplemental material is available online.
From the Department of Health Sciences, University of York, York, United Kingdom.

This study was supported by a grant from ATS Medical Inc, Minneapolis, Minn.

Appendices E1 and E2, Table E1, and References E1 to E32 are available online.

Received for publication Oct 12, 2005; accepted for publication Jan 13, 2006.

Address for reprints: Ole Lund, MD, DSc $(\mathrm{PhD}), 30$ Gresham Close, Darlington, County Durham DL1 2YT, United Kingdom (E-mail: olelund@btinternet.com).

J Thorac Cardiovasc Surg 2006;132:20-6

$0022-5223 / \$ 32.00$

Copyright (๑) 2006 by The American Association for Thoracic Surgery

doi:10.1016/j.jtcvs.2006.01.043
Objective: Choice of a mechanical or biologic valve in aortic valve replacement remains controversial and rotates around different complications with different time-related incidence rates. Because serious complications will always "spill over" into mortality, our aim was to perform a meta-analysis on overall mortality after aortic valve replacement from series with a maximum follow-up of at least 10 years to determine the ageand risk factor-corrected impact of currently available mechanical versus stented bioprosthetic valves.

Methods: Following a formal study protocol, we performed a dedicated literature search of publications during 1989 to 2004 and included articles on adult aortic valve replacement with a mechanical or stented bioprosthetic valve if age, mortality statistics, and prevalences of well-known risk factors could be extracted. We used standard and robust regression analyses of the case series data with valve type as a fixed variable.

Results: We could include 32 articles with 15 mechanical and 23 biologic valve series totaling 17,439 patients and 101,819 patient-years. The mechanical and biologic valve series differed in regard to mean age (58 vs 69 years), mean follow-up (6.4 vs 5.3 years), coronary artery bypass grafting ( $16 \%$ vs $34 \%$ ), endocarditis ( $7 \%$ vs $2 \%$ ), and overall death rate (3.99 vs $6.33 \%$ /patient-year). Mean age of the valve series was directly related to death rate with no interaction with valve type. Death rate corrected for age, New York Heart Association classes III and IV, aortic regurgitation, and coronary artery bypass grafting left valve type with no effect. Included articles that abided by current guidelines and compared a mechanical and biologic valve found no differences in rates of thromboembolism.

Conclusion: There was no difference in risk factor-corrected overall death rate between mechanical or bioprosthetic aortic valves irrespective of age. Choice of prosthetic valve should therefore not be rigorously based on age alone. Risk of bioprosthetic valve degeneration in young and middle-aged patients and in the elderly and old with a long life expectancy would be an important factor because risk of stroke may primarily be related to patient factors.

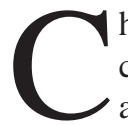
hoice of a prosthetic heart valve in aortic valve replacement (AVR) remains controversial. Current guidelines recommend a mechanical valve in patients aged less than 65 years, but this is based on class II evidence (conflicting evidence or opinion). ${ }^{1}$ The only class I evidence is for choosing a mechanical valve in patients with an expected long life span, ${ }^{1}$ which may be gaining increasing significance for 2 reasons. First, life expectancy is increasing in the general population in the industrialized world, for instance, to 17 years for a 65 -year-old white man in the United States in 2002. ${ }^{2}$ Second, life expectancy calculations in the general population include mortality from chronic debilitating or fatal diseases (eg, dementia and cancer), which are prevalent in the elderly and which contraindicate valve replacement. Even patients aged more than 70 years may achieve normal or longer than average life expectancy after $\mathrm{AVR}^{3-5}$ Long life spans may make 


$$
\begin{aligned}
& \text { Abbreviations and Acronyms } \\
& \text { AC }=\text { anticoagulation } \\
& \text { AVR }=\text { aortic valve replacement } \\
& \text { CL }=\text { confidence limit } \\
& \text { INR }=\text { international normalized ratio } \\
& \text { NYHA }=\text { New York Heart Association } \\
& \text { SD }=\text { standard deviation } \\
& \text { SVD }=\text { structural valve degeneration }
\end{aligned}
$$

structural valve degeneration (SVD) of a bioprosthetic valve almost inevitable in the elderly. ${ }^{5,6}$

Recent years have nonetheless witnessed a shift in prosthetic heart valve preference from mechanical to biologic valves, which is not just explained by the increasing age of patients. Bioprosthetic valves are increasingly being implanted in younger patients ${ }^{7}$ spurred by the belief that third-generation stented xenografts have superior durability compared with previous models. ${ }^{\mathrm{E} 1}$ The risk of SVD accelerates with time (ie, requires long follow-up to become apparent) and is inversely related to age. ${ }^{6}$ High SVD rates of earlier models implanted in younger patients through the 1970s and 1980s resulted in a high proportion of redo AVR causing the preference to swing back toward mechanical valves. Our knowledge base on SVD of third-generation xenografts is consequently based predominantly on valve series with too few young patients who underwent operation too late in the series to have an impact at the present time. Extrapolation from seemingly low rates of SVD in current relatively short "old age series" to younger patients may thus be in error.

Thromboembolism and anticoagulant-related bleeding remain the dominant complications of mechanical valves. The incidence rates of these complications seem to be fairly constant after AVR, but reported rates vary considerably especially for bioprosthetic valves including rates of zero or below the age-specific stroke rates of the background population. ${ }^{6,8}$ Meta-analysis of published data taking both death and the main prosthesis-related complications into account to assess the benefits of mechanical versus biologic valves $^{9-11}$ may thus be misleading. Previous meta-analyses have, furthermore, included series with obsolete mechanical valves $^{9,10}$ and bioprosthetic valve series with follow-up of less than 10 years with related low SVD rates. ${ }^{10,11}$ Finally, meta-analyses have been coupled with microsimulation, which is difficult to comprehend and for which the chosen modeling parameters may introduce bias. ${ }^{9,11}$

A death is an extremely well-defined event, and it would make common sense to postulate that a prosthetic valve complication entity that does not impact mortality of the patients is merely trivial, and none of them are. We therefore had as our primary aim to perform a meta-analysis on pertinent publications from 1989 to 2004 to determine the age-corrected impact of currently available mechanical (bileaflet and single disc) versus stented bioprosthetic (porcine and bovine pericardial) valves on crude mortality after AVR and to correct for the impact of other well-known risk factors using standard and robust regression analysis techniques. To minimize bias related to mortality of various complications with peculiar time effects, which may differ between mechanical and biologic valves, we chose to include only publications with a maximum follow-up of at least 10 years.

\section{Materials and Methods}

We followed a predetermined formal study protocol as suggested by methodologic guidelines for observational studies. ${ }^{12}$ Our primary effect variable was overall death rate. We performed a dedicated literature search of MEDLINE using 2 search engines: PubMed of the US National Library of Medicine and the European EMBASE. We used a broad Boolean search string: "(aorta OR aortic) AND valve AND replacement AND (survival OR mortality OR death rate OR hazard rate)," thus avoiding exclusion terms that could cause articles of interest to be overlooked. We chose articles in English published between 1989 and 2004 because 10-year results with most currently available prosthetic heart valves did not appear earlier. PubMed and EMBASE yielded 2007 and 1954 hits, respectively, and these publications were scrutinized according to the criteria given below.

\section{Inclusion and Exclusion Criteria and Essential Data Extraction}

Articles were included if essential data (defined below) could be extracted from a pure mechanical or stented bioprosthetic AVR series with a longest follow-up of at least 10 years, with at least 75 patients and a maximum of 5\% aged less than 15 years, and with currently available prosthetic valves. We accepted up to $10 \%$ obsolete valve types in mixed mechanical or biologic valve series and excluded articles in which the operative period started before 1975 to avoid time bias. We included only articles that claimed conformance to either the original ${ }^{13}$ or current ${ }^{14}$ guidelines for reporting (or that detailed comparable definitions and method of follow-up), had at most $5 \%$ of patients lost to follow-up, ${ }^{13,14}$ and originated in the industrialized world (Appendix E1). To avoid confounding between case series by factors not related to AVR per se, we excluded series with prevalences of redo operations, concomitant surgery other than coronary artery bypass grafting $(C A B G)$, and operation for active endocarditis of more than $20 \%$. It was essential that we could extract the following data: (1) Death statistics: total number of deaths (early and late) of any cause and total follow-up (accumulated number of patient-years). (2) Demographic and operative data: mean age of the patients with standard deviation or range; prevalence of women, concomitant CABG, concomitant other procedures, redo operation, and operation for active endocarditis. (3) A measure of disease severity: We chose New York Heart Association (NYHA) functional classes because they are usually reported. Other "disease severity" variables including left ventricular function and comorbidities could only be extracted from a fraction of the included articles (Appendix E1). 
TABLE 1. Pertinent demographic, preoperative, and operative data; follow-up; and death rates from the mechanical and bioprosthetic valve series

\begin{tabular}{lccc}
\hline & Mechanical valve series (N = 15) & Biologic valve series (N = 23) & $\boldsymbol{P}$ value $^{*}$ \\
\hline No. of patients & $8578(93-1755)$ & $8861(75-1108)$ & .1 \\
Total follow-up (patient-y) & $54,538(383-9302)$ & $47,281(349-5093)$ & .008 \\
Mean follow-up (y) & $6.4(3.9-10.8)$ & $5.3(2.6-10.1)$ & .05 \\
Total No. of deaths & $2178(15-375)$ & $2992(25-416)$ & .6 \\
Length of operation period (y) & $16.2(5-25)$ & $12.5(3-20)$ & .04 \\
Mean age (y) & $58.0(48-75)$ & $68.8(50-77)$ & $<.001$ \\
Women (\%) & $34.5(21-54)$ & $37.5(15-57)$ & .3 \\
NYHA classes III and IV (\%) & $64.6(29-92)$ & $69.6(49-94)$ & .3 \\
Aortic regurgitation (\%) & $28.7(8-48)$ & $16.5(23-57) \dagger$ & .001 \\
Aortic stenosis (\%) & $50.9(22-72)$ & $68.6(21-100) \dagger$ & .002 \\
Active endocarditis (\%) & $6.8(0-11)$ & $2.2(0-5)$ & $<.001$ \\
Concomitant CABG (\%) & $15.7(0-57)$ & $34.1(0-100)$ & .006 \\
Other concomitant & $4.5(0-20)$ & $7.2(0-16)$ & .2 \\
$\quad$ procedures (\%) & & & .2 \\
Redo operation (\%) & $3.8(0-10)$ & $5.0(0-15)$ & .2 \\
Death rate (\%/patient-y) & $3.99(1.52-8.88)$ & $6.33(1.77-9.09)$ & $<.001$ \\
\hline
\end{tabular}

NYHA, New York Heart Association's functional classification; CABG, coronary artery bypass grafting. *Two-sample $t$ test weighted by number of patients. $†$ Missing in one series (E22). Data are total number of patients, total follow-up, and total number of deaths of included series with range of individual series in parentheses. Mean age, mean follow-up, and length of operation period as well as prevalences (\%) are weighted by number of patients in included series with range of individual series in parentheses. Death rate is rate of all accumulated deaths of included series in relation to total accumulated follow-up with range of individual series in parentheses.

(4) Valve disease: Prevalence of aortic stenosis, regurgitation, and mixed lesion could be recorded in all but 1 of the included articles. Specific exclusion criteria are given per inference from the above. We also excluded pure specialty articles, such as those on the small aortic root/small-sized prosthetic valves and so forth. In case of repeat publications from the same institution, we chose the last published or the one from which the essential data could be extracted. Further details are given in Appendix E1. In total we were able to include 32 articles $^{\mathrm{E} 1-\mathrm{E} 32}$ with 38 valve series, which are detailed in Table E1 relative to valve type.

\section{Statistical Analysis}

All analyses were performed with Stata 8 (Stata Corporation, College Station, Tex). ${ }^{15}$ The strategy was to use overall death rate as the outcome variable in a regression, with valve type as a fixed predictor and other significant predictors including mean age of the valve series added to remove confounding and reduce variability. The overall mortality rate has the advantage of using the whole of the data; every year of observation of a patient is included. It gives all deaths equal weight, except that that early deaths reduce the number of years of follow-up, as well as increase the number of deaths. Because the focus of the investigation was comparison between mechanical and bioprosthetic valve types and this bias will be present in all series, it should have little if any effect on differences. Two regression methods were used: least squares linear regression with death rate as the dependent variable, and negative binomial regression with number of deaths as the dependent variable and patient-years at risk as the exposure variable. We included the latter for comparison because it has been used in similar studies. ${ }^{16}$ We cannot treat study (or article) as a fixed factor, because most studies include only 1 series. We therefore adopted a random-effects approach, treating each study as a cluster and using robust standard errors using the Huber-White-sandwich estimator of variance. ${ }^{15}$ Further details of the statistical analyses are given in Appendix E2.

\section{Results}

The 32 articles provided 38 case series with a total of 17,439 patients and 101,819 patient-years. The maximum follow-up period in a series varied between 10 and 25 years. There were a total of 5170 deaths (936 early and 4234 late). Operations were performed between 1975 and 2002. Table 1, Appendix E1, and Table E1 detail the variables that could be extracted from the 15 mechanical and 23 bioprosthetic valve series. The mechanical valve series were on average larger with longer follow-up and had lower weighted (by total number of patients in each series) mean age and prevalence of CABG but higher prevalence of operation for active endocarditis than the biologic valve series. There was a large difference in mean age distribution between mechanical and biologic valve series but with a considerable overlap (Figure 1). Adjusting for an age impact on mortality without obscuring any real effect should thus be possible.

All variables (Table 1, Appendix E1) were screened for an association with death rate. Patients with mechanical valves had significantly lower mortality than patients with biologic valves $(P<.0001)$. Mean age was strongly related to death rate $(P<.0001$; Figure 2$)$. Adjustment for age eliminated the valve type effect $(P=.8)$. To examine whether there was an 


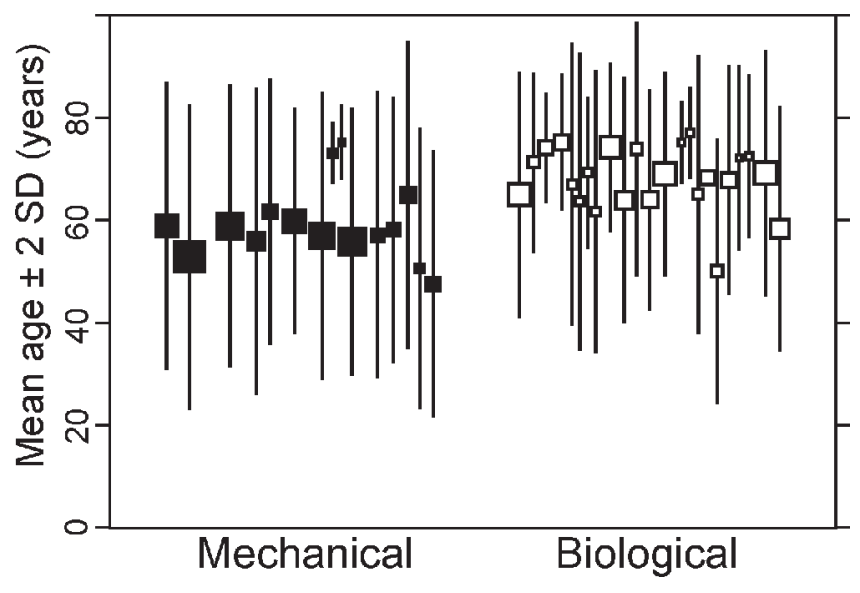

Figure 1. Mean age $(\square) \pm 2$ standard deviations (SDs) of the $\mathbf{1 5}$ mechanical and 23 bioprosthetic valve series. Areas of the squares are proportional to the total follow-up (patient-y) in each valve series.

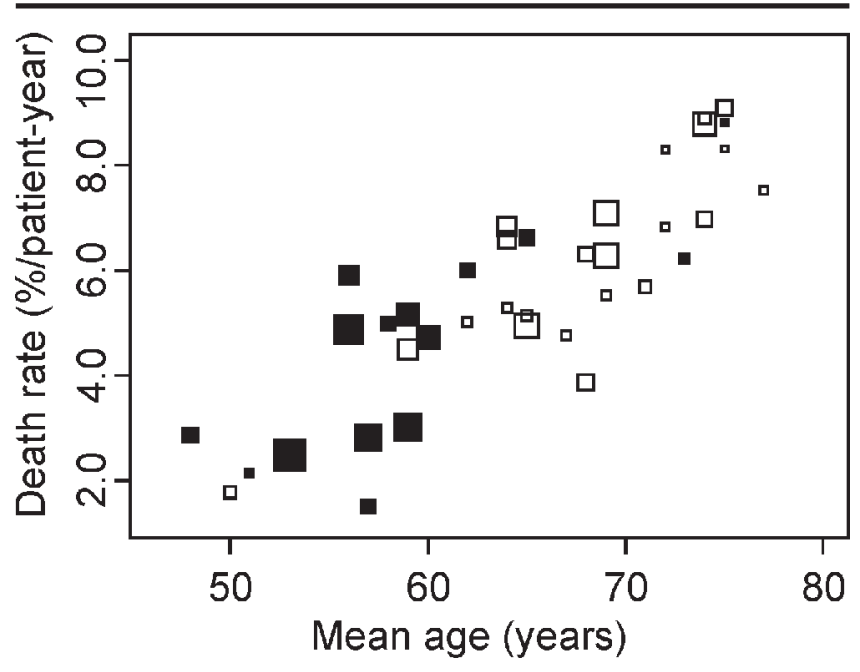

Figure 2. Total death rate of the 15 mechanical ( $\square$ ) and 23 bioprosthetic $(\square)$ valve series in relation to mean age of each series. Areas of the squares are proportional to the total follow-up (patient-y) in each valve series. interaction between valve type and age we modeled an interaction term in the least squares regression model by multiplying mean age by 0 for mechanical valve and by 1 for biologic (and vice versa); this enables the slope of the age relationship with death rate to be different for the 2 valve types, which was not significant $(P=.50)$. When corrected for age in the regression model each of the following variables individually maintained a significant effect on death rate: concomitant CABG, NYHA classes III and IV, aortic regurgitation, aortic stenosis, and active endocarditis.

\section{Least Squares Regression Analysis of Death Rate}

We kept valve type and mean age in the model and eliminated the other potentially significant risk factors identified above one by one in order of the highest $P$ value greater than .05. Mean age remained the strongest risk factor followed by NYHA classes III and IV, and aortic regurgitation (Table 2). After correction for the impact of these risk factors the estimated difference in death rates between valve types (biologic minus mechanical) was -0.23 deaths per 100 patient-years (95\% confidence limit [CL]: -0.99 to $+0.63, P=.5$ ).

Negative Binomial Regression Analysis of Death Rate The final model included age and CABG (Table 2). The estimated rate ratio (biologic/mechanical) was $0.94(95 \%$ CL $0.79-1.10, P=.4)$. To compare the results of the regression analyses we converted the death rate difference estimates from the least squares regression analysis into a ratio; we took the overall weighted mean death rate, added the valve effect, and then divided by the overall rate. This gave an estimated rate ratio of 0.95 (95\% CL 0.81-1.10, $P$ $=.5)$, which is similar to the ratio from the negative binomial regression.

\section{Discussion}

The present meta-analysis of long-term results after AVR is the largest conducted in terms of total number of patients, total number of deaths, and total follow-up available for

TABLE 2. Final regression models of death rate analysis*

\begin{tabular}{|c|c|c|c|c|c|c|}
\hline \multirow[b]{2}{*}{ Predictor variable } & \multicolumn{2}{|l|}{$\mathbf{A}$} & \multicolumn{3}{|c|}{ B } & \multirow[b]{2}{*}{$P$ value } \\
\hline & b & SE & $P$ value & b & SE & \\
\hline Mechanical vs bioprosthetic valve* & -2.34 & 3.69 & .5 & 0.94 & 0.082 & .4 \\
\hline Higher mean age (per year)† & 1.53 & 0.41 & $<.001$ & 1.04 & 0.006 & $<.001$ \\
\hline NYHA classes III and IV & 28.7 & 7.36 & $<.001$ & l & / & / \\
\hline Aortic regurgitation $\ddagger$ & -60.0 & 21.70 & .01 & / & / & l \\
\hline Concomitant CABG $\ddagger$ & l & / & l & 1.51 & 0.24 & .01 \\
\hline Constant & -46.4 & 28.3 & .11 & / & / & / \\
\hline
\end{tabular}

*A, least squares regression (estimating effect on death rate); $B$, negative binomial regression (estimating effect on ratio, biologic/mechanical, of death rates). NYHA, New York Heart Association's functional classification; $C A B G$, coronary artery bypass grafting; $b$, coefficient; $S E$, robust standard error. $\mathrm{F}$ test of final model: $P<.0001$ for both $A$ and $B$. *Entered into model with value of 1 if mechanical valve series and 2 if biologic series. $†$ Entered into model with mean age of individual valve series. $\$$ Entered into model with prevalence (proportion) in individual valve series. 
analysis. The present setup involves other advantages aimed at reducing bias. First, we included only series detailing valves that are currently available for AVR. Second, we exclusively analyzed series with a maximum follow-up of at least 10 years to minimize bias especially secondary to low rates of SVD and related deaths in shorter follow-up bioprosthetic valve series. Third, we chose to analyze only mortality, thus avoiding attempts at correcting for the impact of specific valve-related complications with possible "recording bias" especially in regard to bleeding and thromboembolism but also SVD in bioprosthetic valve series (cf. Discussion paragraphs below). Fourth, we managed to correct mortality differences between mechanical and biologic valves for the impact of a preoperative measure of heart disease severity, NYHA classes III and IV, which has to our knowledge not been achieved before.

The main result of the present analysis is simple and clear: There was no significant difference in death rate between mechanical and bioprosthetic valves when corrected for age and well-known risk factors with no interaction between age and valve type, that is, we could find no difference irrespective of age. The strong impact of age, advanced NYHA class, and concomitant CABG on mortality after AVR needs no explanation; these risk factors have been identified in countless articles. Aortic regurgitation had a negative regression coefficient in the least squares regression model, indicating a reduction in death rate. The explanation probably is that age and NYHA classes III and IV had statistically far stronger impact in the model, thus leaving "young patient in good NYHA class" for aortic regurgitation. This is strengthened by the fact that we were testing case series data and not individual patient data: Patients with aortic regurgitation are younger on average than those with aortic stenosis ${ }^{\mathrm{E} 2}$ and will then dominate in series with a low mean age. The fact that the regression models made perfect clinical sense is an important strength of our results. It also indicates that correction for important risk factors is crucial for a meta-analysis to make sense.

We could not analyze the influence of small valve (eg, prevalence of valve size $\leq 21 \mathrm{~mm}$ ) because such data were available in only a fraction of the included valve series (Appendix E1). An impact of prosthetic valve to patient size mismatch seems to have been noted primarily in studies dominated by stented porcine valves. ${ }^{17}$ Small stented porcine valves have always been problematic, and many surgeons avoid using stented bioprostheses smaller than 23 $\mathrm{mm}$, implanting a mechanical valve instead irrespective of age. ${ }^{18}$ Blackstone and coworkers, ${ }^{19}$ analyzing 13,258 patients with AVR from several centers, noted that small bioprosthetic valves that potentially could cause size mismatch were rarely implanted. Several of the presently included bioprosthetic valve series did not include 19-mm valves. ${ }^{\mathrm{E} 19, \mathrm{E} 25, \mathrm{E} 30, \mathrm{E} 32}$ One may thus assume that mechanical valves often serve as "bail-out" valves for bioprostheses, which may compromise some mechanical valve series.

There were only 2 biologic valve series ${ }^{\mathrm{E} 21, \mathrm{E} 22}$ with subjects with a mean age less than 60 years in whom the majority of the mechanical valve series were located, which is a weakness of the present study. The group with a young mean age is the group for which one would especially expect an impact of bioprosthetic valve SVD. One of the two "young" bioprosthetic valve series with a decent follow-up was small, ${ }^{\text {E21 }}$ whereas the other had a maximum follow-up of only 12 years. ${ }^{\text {E22 }}$ In general, the included bioprosthetic valve series had a mean follow-up of only 5.3 years, which may be too short to involve an impact of SVD-related mortality and thus may have significantly skewed the present results.

There are 2 more problems associated with gauging the risk of SVD and its impact. Many of the presently included articles report only freedom from explant because of $S V D^{\mathrm{E} 1, \mathrm{E} 17, \mathrm{E} 18, \mathrm{E} 29, \mathrm{E} 32}$ or indicate that more than $80 \%$ with SVD actually underwent a redo operation. ${ }^{\mathrm{E} 23, \mathrm{E} 27, \mathrm{E} 28}$ All of those studies were retrospective and did not report regular echocardiographic follow-up, and many patients with SVD may thus have been overlooked. In a large 25-year study of first-time AVR with allografts, involving annual echocardiography, from a center renowned for accepting patients for redo AVR who had been turned down elsewhere, 258 patients with significant SVD were identified but only $53 \%$ underwent a redo AVR. ${ }^{20}$ Furthermore, the 5-year survival after the diagnosis of SVD was 78\% ( \pm a standard error of $3 \%$ ) with redo AVR but only $33 \%( \pm 5 \%)$ without; patients who were not offered a redo AVR were on average 12 years older and had a 3-fold higher prevalence of concomitant CABG at the primary AVR than those who were (previously unpublished analysis by OL). The patients who were not offered a redo operation had obviously become too old or sick with a risk associated with reoperation that was deemed unacceptably high. Remarkably, the 5-year survival after the first appearance of congestive heart failure in the general population is almost exactly similar to the above poor 5-year survival after unoperated SVD. ${ }^{21}$ This means that freedom from explant (redo) because of SVR tells only half the tale, and that SVD is a very serious complication. Without a redo operation the prognosis is extremely poor, but the risk of reoperation is high with death and serious complications in more than $80 \%$ of elderly patients ${ }^{22}$ who are thus less likely to be given the option. A recent analysis of 12-year freedom from SVD in first-, second-, and thirdgeneration stented bioprosthetic valves indicated that differences in mean age of the valve series rather than valve design was the decisive factor. ${ }^{6}$ One may thus suspect that it is not in the best interest of many patients, young in general and old with long life expectancy, to be offered a bioprosthesis. 
The main problem with mechanical valves is the need for lifelong oral anticoagulant treatment. Bleeding and thromboembolism generally account for some $80 \%$ of valverelated complications associated with bileaflet disc valves. ${ }^{\text {E2 }}$ However, the rate of thromboembolism has in general been halved in aortic bileaflet disc valves compared with caged ball valves on similar "old high-intensity" anticoagulant treatment. ${ }^{23} \mathrm{~A}$ decrease of the international normalized ratio (INR) to the currently recommended level (2.0-3.0) for bileaflet disc valves resulted in a further reduction in overall complication rates. ${ }^{24}$ It is well established that patient self-management of oral anticoagulation (AC) treatment manages to keep INR within the desired interval significantly more often than with conventional management, which has resulted in a further decrease of complication rates. ${ }^{25}$ Two large studies pooling data from $34^{26}$ and $46^{27} \mathrm{AC}$ clinics indicated that the risk of bleeding was related to the primary indication for oral AC treatment, with the lowest risk in the group with a prosthetic heart valve and an INR target of 2.0 to 3.0 and a death rate close to that of the background population. ${ }^{27}$

Several pertinent factors may indicte that it would be extremely difficult to engage bleeding and thromboembolic complications in a meta-analysis of mechanical versus biologic valve performance. The reported complication rates vary within the same mechanical valve type, but the variability is especially high with biologic valves. ${ }^{6}$ In the present bioprosthetic valve series with a mean age of 71 to 74 years and claiming conformance to current guidelines, ${ }^{14}$ the rates of thromboembolism varied from $1.40 \%$ to $6.45 \%$ per patient-year. ${ }^{\text {E18,E20,E26,E30 }}$ The bleeding rates ranged from nearly nothing to $1.18 \%$ /patient-year even though the guidelines clearly specify that all bleeding events must be recorded also in patients who are not on oral AC or antiplatelet treatment. ${ }^{14}$ Limited emphasis has traditionally been put on thromboembolism and bleeding in bioprosthetic valve series partly because of the dogma that biologic valves are not thrombogenic and do not require AC treatment, which possibly explains reporting standards. A bioprosthetic valve does not protect a patient from the "normal occurrence" of, for instance, gastrointestinal, urogenital, and cerebral bleeding or from the "background rate" of stroke in general, ${ }^{3,8}$ which "trickles over into mortality" whether the authors reported thromboembolism and bleeding or not. Neither does a biologic prosthetic valve protect the patient from requiring oral $\mathrm{AC}$ treatment for the usual (nonprosthetic valve) indications, and more than $20 \%$ of patients have been reported to be taking oral warfarin at a mean of 2.6 to 5.8 years after AVR. ${ }^{\mathrm{E} 13, \mathrm{E} 18, \mathrm{E} 30}$ It has been shown that patients with a beneficial preoperative risk score obtained an age- and gender-specific normal rate of stroke (thrombotic, embolic, bleeding) and normal survival in the long term after AVR despite an obsolete mechanical valve and high-intensity AC treatment. ${ }^{3}$ This is in accordance with the discovery by Butchart and coworkers ${ }^{28}$ that nearly all patients with an aortic disc valve and a cerebrovascular event had at least 1 of the main risk factors for stroke that are also operational in the general population. This would indicate that the composition of a patient material has as much or higher impact on the rates of cardiovascular events as has the valve type. All 3 of the presently included articles that abided by the current guidelines ${ }^{14}$ and compared a mechanical and biologic AVR series with a mean age greater than 70 years reported similar rates of thromboembolism ${ }^{\mathrm{E} 11, \mathrm{E} 13, \mathrm{E} 31}$ and bleeding. ${ }^{\mathrm{E} 11}$

Meta-analysis of randomized studies has become the gold standard in evidence-based medicine, but heart valve research has not lent itself easily to randomization because of the extended time required to get meaningful results. Only 2 randomized trials between mechanical and bioprosthetic valves have been published since 1989: the Edinburgh $^{29}$ and Veterans Affairs trials. ${ }^{30}$ Both trials used valves that are now obsolete and pooled patients with isolated AVR, isolated mitral valve replacement, and multiple valve replacement, thus making interpretations difficult.

\section{Conclusion}

We found no difference in the overall death rate of patients receiving either mechanical or bioprosthetic aortic valves irrespective of age. Mortality differences between mechanical and biologic valves disappeared when corrected for age and the effect of well-known risk factors, namely, CABG and NYHA classes III and IV. An initial implication may be that choice of prosthetic valve should not be rigorously based on age alone. A narrowing of the gap between mechanical and bioprosthetic valves in regard to the incidence rates of bleeding and thromboembolism because of evolving reporting standards may change the concept of valve choice altogether. Bioprosthetic valve SVD is a worrisome prospect in young and middle-aged patients but also in the elderly with a long life expectancy. The time-related impact of bioprosthetic valve SVD, yet to be more fully experienced in all age groups, may impact even further on future choice of a prosthetic valve.

\section{References}

1. Bonow RO, Carabello B, De Leon AC, et al. Guidelines for the management of patients with valvular heart disease. A report of the American College of Cardiology/American Heart Association task force on practice guidelines. J Am Coll Cardiol. 1998;32:1486-8.

2. Arias E. United States life tables, 2002. National Vital Statistics Reports; vol 53 no 6. Hyattsville, MD: National Center for Health Statistics; 2004.

3. Lund O, Magnussen K, Knudsen M, Pilegaard H, Nielsen TT, Albrechtsen OK. The potential for normal long term survival and morbidity rates after valve replacement for aortic stenosis. $J$ Heart Valve Dis. 1996;5:258-67. 
4. Lund O, Nielsen TT, Magnussen K, Pilegaard HK, Knudsen MA. Valve replacement for calcified aortic stenosis in septuagenarians infers normal life-length. Scand J Thorac Cardiovasc Surg. 1991;25: 37-44.

5. Wheatley DJ. The threshold age in choosing biological versus mechanical prostheses in Western countries. J Heart Valve Dis. 2004; 13:S9 1-S4.

6. Grunkemeier GL, Naftel DC, Starr A, Rahimtoola SH. Long-term performance of heart valve prostheses. Curr Probl Cardiol. 2000;25: 73-154.

7. Dagenais F, Cartier P, Voisine P, et al. Which valve should we select for the 45- to 65-year-old age group requiring aortic valve replacement? J Thorac Cardiovasc Surg. 2005;129:1041-9.

8. Rothwell PM, Coull AJ, Giles MF, et al. Change in stroke incidence, mortality, case-fatality, severity, and risk factors in Oxfordshire, UK from 1981 to 2004 (Oxford Vascular Study). Lancet. 2004;363:192533.

9. Birkmeyer NJ, Birkmeyer JD, Tosteson AN, Grunkemeier GL, Marrin CA, O'Connor GT. Prosthetic valve type for patients undergoing aortic valve replacement: a decision analysis. Ann Thorac Surg. 2000;70: 1946-52.

10. Kassai B, Gueyffier F, Cucherat M, Boissel JC. Comparison of bioprosthesis and mechanical valves, a meta-analysis of randomised clinical trials. Cardiovasc Surg. 2000;8:477-83.

11. Puvimanasinghe JP, Takkenberg JJ, Edwards MB, et al. Comparison of outcomes after aortic valve replacement with a mechanical valve or a bioprosthesis using microsimulation. Heart. 2004;90:1172-8.

12. Stroup DF, Berlin JA, Morton SC, et al. Meta-analysis of observational studies in epidemiology: a proposal for reporting. JAMA. 2000;283: 2008-12.

13. Edmunds LH, Clark RE, Cohn LH, Miller DC, Weisel RD. Guidelines for reporting morbidity and mortality after cardiac valvular operations. J Thorac Cardiovasc Surg. 1988;96:351-3.

14. Edmunds LH, Clark RE, Cohn LH, Grunkemeier GL, Miller DC, Weisel RD. Guidelines for reporting morbidity and mortality after cardiac valvular operations. J Thorac Cardiovasc Surg. 1996;112:70811.

15. Stata Release 8 Base Reference Manual. College Station, TX: Stata Press; 2003.

16. Grunkemeier GL, Wu YX. "Our complication rates are lower than theirs": statistical critique of heart valve comparisons. J Thorac Cardiovasc Surg. 2003;125:290-300.
17. Rao V, Jamieson WR, Ivanov J, Armstrong S, David T. Prosthesispatient mismatch affects survival after aortic valve replacement. Circulation. 2000;102(Suppl 3):III5-9.

18. Bech-Hanssen O, Caidahl K, Wall B, Myken P, Larsson S. Influence of aortic valve replacement, prosthesis type, and size on functional outcome and ventricular mass in patients with aortic stenosis. J Thorac Cardiovasc Surg. 1999;118:57-65.

19. Blackstone EH, Cosgrove DM, Jamieson WR, et al. Prosthesis size and long-term survival after aortic valve replacement. J Thorac Cardiovasc Surg. 2003;126:783-96.

20. Lund O, Chandrasekaran V, Grocott-Mason R, et al. Primary aortic valve replacement with allografts over twenty-five years: valve-related and procedure-related determinants of outcome. J Thorac Cardiovasc Surg. 1999;117:77-90.

21. Ho KKL, Anderson KM, Kannel WB, Grossman W, Levy D. Survival after the onset of congestive heart failure in Framingham heart study subjects. Circulation. 1993;88:107-15.

22. Kirch M, Nakashima K, Kubota S, et al. The risk of reoperative heart valve procedure in octogenarian patients. J Heart Valve Dis. 2004;13: 991-6.

23. Cannegieter SC, Rosendaal FR, Briet E. Thromboembolic and bleeding complications in patients with mechanical heart valve prostheses. Circulation. 1994;89:635-41.

24. Acar J, Iung B, Boissel JP, et al. AREVA: multicenter randomized comparison of low-dose versus standard-dose anticoagulation in patients with mechanical prosthetic heart valves. Circulation. 1996;94: 2107-12.

25. Völler H, Dovifat C, Glatz J. Home management of anticoagulation. Eur Heart J Suppl. 2001;3(Suppl Q):Q4 4-9.

26. Palareti G, Leali N, Coccheri S, et al. Bleeding complications of oral anticoagulant treatment: an inception-cohort, prospective collaborative study (ISCOAT). Lancet. 1996;348:423-8.

27. Oden A, Fahlen M. Oral anticoagulation and risk of death: a medical record linkage study. BMJ. 2002;325:1073-5.

28. Butchart EG, de la Santa PM, Rooney SJ, Lewis PA. Arterial risk factors and ischemic cerebrovascular events after aortic valve replacement. J Heart Valve Dis. 1995;4:1-8.

29. Oxenham H, Bloomfield P, Wheatley DJ, et al. Twenty year comparison of a Bjork-Shiley mechanical heart valve with porcine bioprostheses. Heart. 2003;89:715-21.

30. Hammermeister K, Sethi GK, Henderson WG, Grover FL, Oprian C, Rahimtoola SH. Outcomes 15 years after valve replacement with a mechanical versus a bioprosthetic valve: final report of the Veterans Affairs randomized trial. J Am Coll Cardiol. 2000;36:1152-8.

\section{Availability of Journal back issues}

As a service to our subscribers, copies of back issues of The Journal of Thoracic and Cardiovascular Surgery for the preceding 5 years are maintained and are available for purchase from Mosby until inventory is depleted. Please write to Mosby, Subscription Customer Service, 6277 Sea Harbor Dr, Orlando, FL 32877, or call $800-654-2452$ or $407-345-4000$ for information on availability of particular issues and prices. 
TABLE E1. The included 38 valve series relative to specific prosthetic valve types

\begin{tabular}{|c|c|c|c|c|}
\hline & [Reference] & No. of patients & Total follow-up (patient-y) & Death rate $\% /$ patient- \\
\hline \multicolumn{5}{|l|}{ Mechanical valve series } \\
\hline St Jude bileaflet disc, $\mathrm{N}=10^{*}$ & [E2-E11] & 4069 (93-773) & $24,356(383-6419)$ & $4.35(1.52-8.88)$ \\
\hline Mixed disc valve, $\mathrm{N}=3 \dagger$ & {$[\mathrm{E} 12, \mathrm{E} 13]$} & $2957(222-1755)$ & $17,368(865-9302)$ & $2.88(2.48-6.13)$ \\
\hline Medtronic-Hall tilting disc, $\mathrm{N}=2$ & {$[\mathrm{E} 14, \mathrm{E} 15]$} & $1552(736-816)$ & $12,814(5120-7694)$ & $4.82(4.73-4.87)$ \\
\hline \multicolumn{5}{|l|}{ Bioprosthetic valve series } \\
\hline CE Perimount pericardial, $\mathrm{N}=6$ & [E1, E16-E20] & $1852(75-589)$ & $9643(470-2556)$ & $5.81(4.04-8.30)$ \\
\hline CE porcine standard, $\mathrm{N}=5$ & [E9, E21-E24] & $1792(94-572)$ & $10,465(862-3375)$ & $5.14(1.77-6.84)$ \\
\hline CE porcine supra-annular, $\mathrm{N}=3$ & {$[\mathrm{E} 19, \mathrm{E} 25, \mathrm{E} 26]$} & $1307(75-1108)$ & $5918(513-4735)$ & $8.25(5.52-8.79)$ \\
\hline Hancock II and MO porcine, $\mathrm{N}=3$ & [E27-E29] & $1645(132-843)$ & $10,807(857-5093)$ & $5.96(4.94-7.09)$ \\
\hline Mitroflow pericardial, $\mathrm{N}=3$ & {$[\mathrm{E} 11, \mathrm{E} 23, \mathrm{E} 30]$} & $643(113-403)$ & $2673(572-1270)$ & $7.48(5.29-8.90)$ \\
\hline Mixed biologic $N=2 \ddagger$ & {$[\mathrm{E} 13, \mathrm{E} 31]$} & $602(133-469)$ & $2726(349-2377)$ & $8.99(8.31-9.09)$ \\
\hline Biocor porcine, $\mathrm{N}=1$ & [E32] & 1029 & 5049 & 6.28 \\
\hline
\end{tabular}

Data are total number of patients and total follow-up of included valve series with range of individual series in parenthesis; death rate is rate of all accumulated deaths of included series in relation to total accumulated follow-up with range of individual series in parenthesis. $C E$, Carpentier-Edwards. *Reference E4, 7\% obsolete (Silzone sewing ring). †Reference E12, bileaflet disc valves (St Jude, Carbomedics, Sorin, ATS, On-X, Edwards Mira; 2.6\% obsolete: Edwards Duromedics, and Tekna); reference E12, single disc valves (Medtronic-Hall, Sorin, Ultracor; 10\% obsolete: Björk-Shiley); reference E13, bileaflet disc valves (St Jude, Sorin, Carbomedics; $0.5 \%$ obsolete: Edwards Duromedics). $\ddagger$ Reference E13, mixed porcine (CE Porcine Standard, Hancock II, Mosaic, Edwards Prima (stentless, 17\%); 0.3\% obsolete: St Jude X-cell; reference E31, porcine and pericardial valves (CE porcine standard, supra-annular, and Perimount pericardial). The manufacturers for all devices listed are (in alphabetical order): ATS Medical Inc., Minneapolis, Minn (ATS bileaflet disc valve); Edwards Lifesciences, Irvine, Calif (Carpentier-Edwards Perimount pericardial valve; and Porcine Standard and Supra-annular valves; Edwards Prima stentless porcine valve; Edwards Duromedics, Mira, and Tekna bileaflet valves); Koehler Medical Ltd., Lees, UK (Ultracor single disc valve); Medical Carbon Research Institute Inc., Austin, Tx (On-X bileaflet disc valve); Medtronic Inc., Minneapolis, Minn (Hancock II and MO porcine valves; Medtronic-Hall single disc valve; Medtronic Mosaic porcine valve); Shiley Inc., Irvine, Calif (no longer exists; Björk-Shiley single disc valve); Sorin Biomedica, Modena, Italy (Sorin bileaflet and single disc valves); Sorin CarboMedics Inc, Austin, Tx (Carbomedics bileaflet disc valve); Sorin Group Canada, Vancouver, Canada (Mitroflow pericardial valve); and St. Jude Medical Inc., St. Paul., Minn (St. Jude bileaflet disc valve; St. Jude Silzone bileaflet disc valve; Biocor porcine valve; X-cell porcine valve).

\section{Appendix E1. Further details of the included valve series}

Table E1 details the included valve series relative to the specific prosthetic valve. In a few instances data were extracted from several articles detailing the same patient series. We contacted the corresponding author of articles published between 2000 and 2004 that potentially could be included but in which essential data were missing and received the requested information for 9 articles. Certain valve types have been modified several times since their introduction (eg, the Carpentier-Edwards standard porcine valve and Perimount bovine pericardial valve, Edwards Lifesciences, Irvine, Calif; and the variations of the St Jude bileaflet disc valve, St Jude Medical Inc, St Paul, Minn) but have retained their original name, whereas others (eg, Sorin's bileaflet and single disc valves, Sorin Biomedica, Modena, Italy) have been renamed with each change. We chose to accept such valve types as current. We included articles originating in the industrialized world defined as North America, Western Europe (Sweden, Finland, Norway, Denmark, Germany, Holland, Belgium, Luxembourg, United Kingdom, Ireland, France, Austria, Switzerland, Italy, Spain, Portugal, and Greece), Australia, New Zealand, and Japan. The following variables could only be extracted from a fraction of the publications and could therefore not be used in the statistical tests: prevalence of small prosthetic valves $(\leq 21 \mathrm{~mm} ; 65 \%)$, prior myocardial infarct (50\%), diabetes (20\%), kidney failure (18\%), hypertension (15\%), poor left ventricular function $(13 \%)$, and so forth.

\section{Appendix E2. Details of the statistical analysis}

For least squares linear regression, the outcome variable, death rate, should follow an approximately normal distribution with uniform variance, which was shown to be the case and substantiated by an approximately linear normal plot. Least squares regression gives the estimated difference between valve types as deaths per 100 patient-years. The case series were weighted by size using the total patient-years of follow-up. Negative binomial regression is a development of Poisson regression, which allows for more variation between the series than the Poisson distribution would allow. This is an approximation because deaths should happen randomly in time, but in AVR series the death rate is high at the beginning, decreases after the immediate postoperative period, and increases over the more than 10 years of follow-up as subjects age. Thus, we would not expect a uniform death rate over follow-up, and deaths would not be generated by a Poisson process.

We cannot treat study (or article) as a fixed factor, because most studies include only 1 series. We therefore adopted a random effects approach, treating each study as a cluster and using robust standard errors using the Huber-White-sandwich estimator of variance; ${ }^{15}$ the effect is to increase the standard error and reduce power and precision when there is more than 1 series of the same valve type (eg, 2 different mechanical valves) in a cluster, and to reduce the standard error and increase power and precision when there are series of different valve types (mechanical vs biologic) in a cluster.

The difference between valve types was adjusted for by variables that may influence survival. There are 2 reasons for 
doing this. A variable that is related to survival and that differs between patients given different valve types may either produce a spurious difference between them or mask one that is otherwise present. For example, patients given mechanical valves tend to be younger with a smaller annual risk of death than patients given bioprosthetic valves. The second reason for adjustment is that we may have variables that predict survival, even though they do not differ between patients given the 2 valve types. Adjusting for such variables will not change the estimate of the difference between valve types, but will reduce the random variation and improve the precision of the estimate. We cannot adjust for all the variables recorded because we have data only at the level of the case series, that is, 38, and a good guideline is that we should have at least 10 observations per variable; a regression equation with more than 4 predicting variables may be unreliable. Because each series has only 1 type of valve (mechanical or bioprosthetic), the analysis should be efficient for estimating the difference between valves. It will not be efficient for estimating the effect of other factors. A variable that may greatly influence survival at the individual level may not produce differences between the case series because too few patients had the adverse characteristic or the series did not differ much in the proportion of patients with the variable.

We had data on NYHA classes in all articles but in only 5 articles as mean and standard deviation (SD). We could extract the proportion of patients in NYHA classes III or IV in all other series. We calculated the mean and SD from 22 series in which all 4 classes were given, then used proportion in classes III and IV as the dichotomous outcome variable and mean NYHA class and SD as the predictors in a logistic regression. This gave the log odds of being in class III or IV, which we converted to a proportion. The observed and predicted proportions in NYHA classes III or IV were closely and linearly related $(r=0.98)$. We then used the same equation to calculate the proportion of patients in NYHA classes III or IV in the 5 series in which we only had mean NYHA class and SD.

\section{Online References}

E1. Banbury MK, Cosgrove DM, White JA, Blackstone EH, Frater RW, Okies JE. Long-term results of the Carpentier-Edwards pericardial aortic valve: a 12-year follow-up. Ann Thorac Surg. 1998;66(Suppl):S7 3-S6.

E2. Lund O, Nielsen SL, Arildsen H, Ilkjaer LB, Pilegaard HK. Standard aortic St. Jude valve at 18 years: performance profile and determinants of outcome. Ann Thorac Surg. 2000;69:1459-65.

E3. Aoyagi S, Oryoji A, Nishi Y, Tanaka K, Kosuga K, Oishi K. Long-term results of valve replacement with the St. Jude Medical valve. J Thorac Cardiovasc Surg. 1994;108:1021-9.

E4. Ikonomidis JS, Kratz JM, Crumbley AJ, et al. Twenty-year experience with the St Jude Medical mechanical valve prosthesis. J Thorac Cardiovasc Surg. 2003;126:2022-31.

E5. Baudet EM, Puel V, McBride JT, et al. Long-term results of valve replacement with the St. Jude Medical prosthesis. J Thorac Cardiovasc Surg. 1995;109:858-70.

E6. Smith JA, Westlake GW, Mullerworth MH, Skillington PD, Tatoulis $\mathrm{J}$. Excellent long-term results of cardiac valve replacement with the St Jude Medical valve prosthesis. Circulation. 1993;88(Pt 2):II 4954.

E7. Debetaz LF, Ruchat P, Hurni M, et al. St. Jude Medical valve prosthesis: an analysis of long-term outcome and prognostic factors. J Thorac Cardiovasc Surg. 1997;113:134-48.
E8. Nakano K, Koyanagi H, Hashimoto A, et al. Twelve years' experience with the St. Jude Medical valve prosthesis. Ann Thorac Surg. 1994;57:697-702.

E9. Peterseim DS, Cen YY, Cheruvu S, et al. Long-term outcome after biologic versus mechanical aortic valve replacement in 841 patients. J Thorac Cardiovasc Surg. 1999;117:890-7.

E10. Khan S, Chaux A, Matloff J, et al. The St. Jude Medical valve. Experience with 1,000 cases. J Thorac Cardiovasc Surg. 1994;108: 1010-9.

E11. Ninet J, Tronc F, Robin J, Curtil A, Aleksic I, Champsaur G. Mechanical versus biological isolated aortic valvular replacement after the age of 70: equivalent long-term results. Eur J Cardiothorac Surg. 1998;13:84-9.

E12. Vitale N, de Feo M, de Siena P, et al. Tilting-disc versus bileaflet mechanical prostheses in the aortic position: a multicenter evaluation. J Heart Valve Dis. 2004;13(Suppl):S27-S34.

E13. Milano A, Guglielmi C, De Carlo M, et al. Valve-related complications in elderly patients with biological and mechanical aortic valves. Ann Thorac Surg. 1998;66(Suppl):S82-S7.

E14. Nitter-Hauge S, Abdelnoor M, Svennevig JL. Fifteen-year experience with the Medtronic-Hall valve prosthesis: a follow-up study of 1104 consecutive patients. Circulation. 1996;94(Suppl):II105-II8.

E15. Butchart EG, Li HH, Payne N, Buchan K, Grunkemeier GL. Twenty years' experience with the Medtronic Hall valve. J Thorac Cardiovasc Surg. 2001;121:1090-100.

E16. Pellerin M, Mihaileanu S, Couetil JP, et al. Carpentier-Edwards pericardial bioprosthesis in aortic position: long-term follow-up 1980 to 1994. Ann Thorac Surg. 1995;60(Suppl):S292-S5.

E17. Aupart MR, Sirinelli AL, Diemont FF, Meurisse YA, Dreyfus XB, Marchand MA. The last generation of pericardial valves in the aortic position: ten-year follow-up in 589 patients. Ann Thorac Surg. 1996;61:615-20.

E18. Dellgren G, David TE, Raanani E, Armstrong S, Ivanov J, Rakowski $\mathrm{H}$. Late hemodynamic and clinical outcomes of aortic valve replacement with the Carpentier-Edwards Perimount pericardial bioprosthesis. J Thorac Cardiovasc Surg. 2002;124:146-54.

E19. Le Tourneau T, Vincentelli A, Fayad G, et al. Ten-year echocardiographic and clinical follow-up of aortic Carpentier-Edwards pericardial and supraannular prosthesis: a case-match Study. Ann Thorac Surg. 2002;74:2010-5.

E20. Mistiaen W, Van Cauwelaert P, Muylaert P, Wuyts F, Harrisson F, Bortier $\mathrm{H}$. Risk factors and survival after aortic valve replacement in octogenarians. J Heart Valve Dis. 2004;13:538-44.

E21. Bernal JM, Rabasa JM, Lopez R, Nistal JF, Muniz R, Revuelta JM. Durability of the Carpentier-Edwards porcine bioprosthesis: role of age and valve position. Ann Thorac Surg. 1995;60(Suppl):S248-S52.

E22. Jamieson WR, Allen P, Miyagishima RT, et al. The CarpentierEdwards standard porcine bioprosthesis. A first-generation tissue valve with excellent long-term clinical performance. $J$ Thorac Cardiovasc Surg. 1990;99:543-61.

E23. Houel R, Le Besnerais P, Soustelle C, et al. Lack of durability of the Mitroflow valve does not affect survival. J Heart Valve Dis. 1999;8:368-74.

E24. Orszulak TA, Schaff HV, Mullany CJ, et al. Risk of thromboembolism with the aortic Carpentier-Edwards bioprosthesis. Ann Thorac Surg. 1995;59:462-8.

E25. de la Fuente A, Sanchez R, Imizcoz A, Fernandez JL, Olaz F, Moriones I. Intact Medtronic and Carpentier Edwards S.A.V.: clinical and hemodynamic outcomes over 13 years. Cardiovasc Surg. 2003; 11:139-44.

E26. Logeais Y, Langanay T, Leguerrier A, et al. Aortic CarpentierEdwards supraannular porcine bioprosthesis: a 12-year experience. Ann Thorac Surg. 1999;68:421-5.

E27. Legarra JJ, Llorens R, Catalan M, et al. Eighteen-year follow up after Hancock II bioprosthesis insertion. J Heart Valve Dis. 1999;8:16-24

E28. David TE, Ivanov J, Armstrong S, Feindel CM, Cohen G. Late results of heart valve replacement with the Hancock II bioprosthesis. J Thorac Cardiovasc Surg. 2001;121:268-77.

E29. Cohn LH, Collins JJ Jr, Rizzo RJ, et al. Twenty-year follow-up of the Hancock modified orifice porcine aortic valve. Ann Thorac Surg. 1998;66(Suppl):S30-S4.

E30. Thulin LI, Thilen UJ, Kymle KA. Mitroflow pericardial bioprosthe- 
sis in the aortic position. Low incidence of structural valve deterioration in elderly patients during an 11-year follow-up. Scand Cardiovasc J. 2000;34:192-6.

E31. Akins CW, Hilgenberg AD, Vlahakes GJ, et al. Results of bioprosthetic versus mechanical aortic valve replacement performed with concomitant coronary artery bypass grafting. Ann Thorac Surg. 2002;74:1098-106.

E32. Myken P, Bech-Hanssen O, Phipps B, Caidahl K. Fifteen years follow up with the St. Jude Medical Biocor porcine bioprosthesis. J Heart Valve Dis. 2000;9:415-22. 